\title{
An Integrated Vendor-Buyer Cooperative Inventory Model for Items with Imperfect Quality and Shortage Backordering
}

\author{
Jia-Tzer Hsu ${ }^{1}$ and Lie-Fern $\mathrm{Hsu}^{2}$ \\ ${ }^{1}$ Department of Computer Science and Information Engineering, Hungkuang University, Shalu, \\ Taichung 43302, Taiwan \\ ${ }^{2}$ Department of Management, Zicklin School of Business, Baruch College, The City University of New York, \\ One Bernard Baruch Way, P.O. Box B9-240, New York, NY 10010, USA
}

Correspondence should be addressed to Lie-Fern Hsu, lie-fern.hsu@baruch.cuny.edu

Received 15 April 2012; Revised 9 July 2012; Accepted 27 July 2012

Academic Editor: Henry Schellhorn

Copyright (C) 2012 J.-T. Hsu and L.-F. Hsu. This is an open access article distributed under the Creative Commons Attribution License, which permits unrestricted use, distribution, and reproduction in any medium, provided the original work is properly cited.

\begin{abstract}
We develop a model to determine an integrated vendor-buyer inventory policy for items with imperfect quality and planned backorders. The production process is imperfect and produces a certain number of defective items with a known probability density function. The vendor delivers the items to the buyer in small lots of equally sized shipments. Upon receipt of the items, the buyer will conduct a $100 \%$ inspection. Since each lot contains a variable number of defective items, shortages may occur at the buyer. We assume that shortages are permitted and are completely backordered. The objective is to minimize the total joint annual costs incurred by the vendor and the buyer. The expected total annual integrated cost is derived and a solution procedure is provided to find the optimal solution. Numerical examples show that the integrated model gives an impressive cost reduction in comparison to an independent decision by the buyer.
\end{abstract}

\section{Introduction}

Supply chain management focuses on the material and information flows between facilities and their final customers and has been considered the most popular operations strategy for improving organizational competitiveness nowadays. Cao and Zhang [1] showed that firms have been attempting to achieve greater collaborative advantages with their supply chain partners in the past few decades, and that supply chain collaborative advantages have a bottom-line influence on firm performance. This means that the vendor and the buyer should work together in a cooperative manner towards maximizing their mutual benefits. Integrated inventory management has recently received a great deal of attention. Goyal [2] considered the joint optimization problem of a single vendor and a single buyer, in which he assumed that the vendor's production rate is infinite. Banerjee [3] assumed finite rate of production 
and developed a joint economic-lot-size (JELS) model for the product with a lot-for-lot shipment policy. He demonstrated the advantage of the JELS approach through an analysis of the cost trade-offs (in conjunction with an appropriate price adjustment) from the perspective of each party's optimal position. It was shown that a jointly optimal ordering policy, together with an appropriate price adjustment, could be beneficial economically for both the vendor and the buyer, or at the very least, did not place either at a disadvantage. Goyal and Szendrovits [4] considered a policy that combines a number of increasing shipment sizes which are then followed by a number of equally sized shipments. By relaxing the Banerjee [3] lot-for-lot assumption, Goyal [5] developed a joint total relevant cost model for a single-vendor single-buyer production-inventory system in which each production batch was shipped to the buyer in smaller batches of equal size. Goyal's [5] model was derived based on the assumption that the vendor could supply to the buyer only after completing the entire lot size, and the model was shown to provide a lower or equal joint total relevant cost as compared to the model of Banerjee [3]. Goyal and Gupta [6] reviewed the related literature in integrated vendor-buyer inventory models.

Affisco et al. [7] investigated the one-vendor, many nonidentical buyers JELS policies. Aderohunmu et al. [8] showed that a significant cost reduction could be achieved to the advantage of both the vendor and the buyer in a just-in-time environment when timely cost information was shared between the parties. Lu [9] considered the single-vendor multibuyer integrated inventory problem with the objective of minimizing the vendor's total cost subject to the maximum costs which the buyers were prepared to incur. He assumed that the vendor could supply to the buyer even before completing the entire lot. He found the optimal solution for the single-vendor single-buyer case and presented a heuristic approach for the single-vendor multi-buyer case. Goyal [10] developed a model where the shipment size increases by a factor equal to the ratio between the vendor's production rate and the demand rate of the buyer. Hill [11] illustrated that, in general, neither of the two policies described in Lu [9] and Goyal [10] would be optimal. He generalized the model of Goyal [10] by taking the geometric growth factor as a decision variable, of which the equal shipment size policy and Goyal's [10] policy represent special cases. He also pointed out that the rather complicated nature of the shipment sizes provided by the policy may well mean that these results were of analytical rather than of immediate practical interest. Ha and Kim [12] addressed the necessity of integration between buyer and supplier for effective implementation of the just-in-time (JIT) system. Viswanathan [13] showed that there exists no strategy that obtains the best solution for all possible problem parameters of the two different strategies of equally and unequally sized batch shipments as described in Lu [9] and Goyal [10]. Hill [14] determined the optimal production and inventory policy for a vendor manufacturing to supply to a single buyer. The policy turned out to be a combination of Goyal's [10] policy and an equal shipment size policy.

Hoque and Goyal [15] extended the idea of Goyal and Szendrovits [4] and developed an optimal solution procedure for the single-vendor single-buyer integrated productioninventory system with both equally and unequally sized shipments from the vendor to the buyer and under the capacity constraint of the transport equipment. Goyal and Nebebe [16] provided a method that was easy to implement and conceptually simpler than the methods suggested in Goyal [10] and Hill [11]. Wu and Ouyang [17] considered the integrated singlevendor single-buyer inventory system with shortage. They proposed an algebraic procedure to find the optimal order quantity, the maximum shortage level, and the optimal number of deliveries from the vendor to the buyer per order of the integrated total cost of the vendor and the buyer without using differential calculus. Chung [18] showed that Wu 
and Ouyang's [17] proof of a global cost minimum was incomplete. He then justified the algorithm described in Wu and Ouyang [17]. Ben-Daya and Al-Nassar [19] developed a cost minimization supply chain coordination model for a three-layer supply chain involving suppliers, manufacturers, and retailers and derived a solution procedure for the model. They showed that considerable savings could be obtained if shipments were sent as soon as they were produced in comparison to the scheme that allowed shipments only after the whole lot was produced.

The traditional economic order quantity (EOQ) model assumes that items produced are of perfect quality. Some researchers argue that product quality is not always perfect, but is directly affected by the reliability of the production process used. Therefore, the process may deteriorate and produce defectives or poor-quality items. Salameh and Jaber [20] developed an economic order quantity model where a random proportion of the items in a lot are defective. Huang [21] extended the integrated vendor-buyer inventory model by accounting for imperfect-quality items. He considered the situation where the delivery quantity sent to the buyer was identical for each shipment. Goyal et al. [22] used the Goyal and Cárdenas-Barrón [23] model to determine an optimal integrated vendor-buyer inventory policy for an item with imperfect quality. Huang [24] developed a model to determine an optimal integrated vendor-buyer inventory policy for unreliable production process in an JIT manufacturing environment. The objective is to minimize the total joint annual costs incurred by the vendor and the buyer. He showed that the developed model produces a significant cost reduction when compared with the expected annual integrated cost without JIT philosophy. Lo et al. [25] assumed a varying rate of deterioration, partial backordering, inflation, imperfect production processes, and multiple deliveries and developed an integrated production and inventory model from the perspectives of both the manufacturer and the retailer. Wee et al. [26] extended the approach by Salameh and Jaber [20] to consider permissible shortage backordering and the effect of varying backordering cost values. Maddah and Jaber [27] corrected a flaw in the Salameh and Jaber [20] model by using the renewal reward theorem. They came up with simpler expressions for the expected profit and the order quantity. Yoo et al. [28] proposed a profit-maximizing economic production quantity model that incorporated both imperfect production quality and two-way imperfect inspection, that is, type I inspection error of falsely screening out a proportion of nondefects and disposing of them and type II inspection error of falsely not screening out a proportion of defects, thereby passing them on to customers, resulting in the sales returns of defective items. Cárdenas-Barrón [29] developed an EPQ inventory model with planned backorders for determining the economic production quantity and the size of backorders for a single product, which was made in a single-stage manufacturing process that generated imperfect-quality products and required that all defective products be reworked at the same cycle. Chang and Ho [30] revisited the work of Wee et al. [26] and adopted the suggestion of Maddah and Jaber [27] to use the renewal reward theorem to derive closed-form solutions for the optimal lot size and the maximum shortage level without using differential calculus. Sana [31] investigated an EPL (economic production lot size) model in an imperfect production system in which the production facility may shift from an "in-control" state to an "out-ofcontrol" state at any random time. Khan et al. [32] extended the work of Salameh and Jaber [20] by assuming that the inspection process was not error-free and both type I and type II inspection errors follow a known probability density function. Hsu [33] pointed out a flaw in Khan et al.'s [32] mathematical model and developed a corrected EOQ. J. T. Hsu and L. F. Hsu [34] developed an integrated inventory model for vendor-buyer coordination under an imperfect production process, where the vendor inspects the items while they are being 
produced and delivers good quality items to the buyer in small lots over multiple deliveries. J. T. Hsu and L. F. Hsu [35] pointed out a contradiction between Wee et al.'s [26] and Chang and Ho's [30] mathematical model and assumption and developed a corrected model based on their assumption.

All the integrated vendor-buyer inventory models, except J. T. Hsu and L. F. Hsu's [34], focus on the just-in-time philosophy, that is, shortages are not allowed. However, due to imperfect product quality, shortages may sometimes occur. In practice, planned shortages are often used; for example, companies use planned shortages when the cost of stocking an item exceeds the profit that would come from selling it. Furniture showrooms, for example, do not stock enough furniture to cover all demand, and customers are often asked to wait for their orders to be delivered from suppliers or regional distribution centers. Or when someone decides to buy a new car or a new computer, they choose the features they want on the car or design a particular system for the computer, and then wait for the item to be delivered after a short period of time [36]. The purpose of this paper is to develop an integrated vendor-buyer inventory model for items with imperfect quality and shortage backordering. The rest of this paper is organized as follows. In Section 2, the notation and assumptions used in this paper are introduced. In Section 3, we develop a mathematical model that integrates the vendor's and the buyer's annual cost and takes into consideration imperfect-quality items and shortage backordering. Section 4 provides numerical examples and sensitivity analysis to various parameters to illustrate important aspects of the model. Finally, in Section 5 we summarize and conclude the paper and provide directions for future research.

\section{Notation and Assumptions}

We consider a simple supply chain problem with a single vendor and a single buyer. The buyer has an annual demand rate of $D$ units for the given product, and places regular orders of fixed size $Q_{P}$. The vendor prepares for the repeating flow of orders of size $Q_{P}$ from the buyer by producing items in batches of size $Q_{P}$ and planning to have each batch delivered to the buyer in $n$ shipments, each with a lot of $Q$ units. The vendor fulfills the shipments of $Q$ units with a known and fixed lead time. Since the production process is not perfect, some of the $Q$ units may be defective. Once the buyer receives the lot of $Q$ units, a $100 \%$ screening process is conducted. The buyer satisfies all demand with good quality items and returns to the vendor all defective items. Since all customers are assumed to be willing to wait for a later shipment at some known cost, shortages at the buyer are allowed and backordered. The following notations and assumptions are used in our model.

$Q_{P}$ : The size of a production batch at the vendor

$Q$ : The size of the shipments from the vendor to the buyer

$B$ : The maximum backordering quantity in units at the buyer

$n$ : The number of shipments per batch production run, a positive integer $\left(Q_{P}=n Q\right)$

$D$ : The annual demand at the buyer

$P$ : The annual production rate at the vendor

$S_{v}$ : The setup cost per production run for the vendor

$S_{B}$ : The ordering cost per order for the buyer

$\gamma$ : The defective percentage in $Q$

$f(\gamma)$ : The probability density function of $\gamma$ 
$v$ : The vendor's unit warranty cost per defective item for the buyer

$d$ : The screening cost per unit

$b$ : The backordering cost per unit per year at the buyer

$h_{v}$ : The holding cost per unit per year for the vendor

$h_{B}$ : The holding cost per unit per year for the buyer

$F$ : The freight (transportation) cost per shipment from the vendor to the buyer

$T$ : Time interval between successive shipments of $Q$ units

$T_{1}$ : Period during which the vendor produces

$T_{2}$ : Period during which the vendor supplies from inventory

$T_{c}$ : Cycle time $=T_{1}+T_{2}=n T$

*: The superscript representing optimal value.

Assumptions:

(1) The demand rate is known, constant, and continuous.

(2) The lead time is known and constant.

(3) The defective items exist in lot size $Q$. The defective percentage $\gamma$ has a probability density function $f(\gamma)$. To ensure that the vendor has enough production capacity to produce the buyer's annual demand, it is assumed that $E[\gamma]<1-D / P$.

(4) A $100 \%$ screening process of the lot is conducted at the buyer's place before the beginning of each cycle time $T$. In other words, the screening time is counted as part of the lead time for delivery. All defective items are returned to the vendor upon receipt of the next lot (therefore, there is no extra freight cost for the returned items). A defective item incurs a warranty cost of $v$ for the vendor. The vendor will sell the defective items at a reduced price to a secondary market.

(5) Shortages are completely backordered.

(6) A single product is considered.

(7) There is a single vendor and a single buyer.

\section{Mathematical Model}

\subsection{The Buyer's Cost per Cycle}

Figure 1 depicts the behavior of the nondefective inventory level over time for the buyer. The buyer's inventory cost per cycle consists of costs due to placing an order, transportation, screening, holding, and backordering. The buyer will return the defective items to the vendor upon the receipt of the next lot of $Q$ items. Then, we have

$$
T C_{B}(n, Q, B)=S_{B}+n F+d n Q+h_{B} n\left\{\frac{1}{2} \frac{(Q-\gamma Q-B)^{2}}{D}+\frac{Q^{2} \gamma(1-\gamma)}{D}\right\}+b n \frac{1}{2} \frac{B^{2}}{D}
$$

Note that for the non-defective items, the maximum inventory level is $Q(1-\gamma)-B$, and the minimum inventory level is 0 , so the average inventory level is $(1 / 2)(Q(1-\gamma)-B)$. Since we assume that the buyer will return all defective items to the vendor upon receipt of the next lot, the average inventory level of the defective items is $Q \gamma$. Since $t_{1}=(Q-\gamma Q-B) / D$ and $T=$ $Q(1-\gamma) / D$, the buyer's holding cost per cycle is $h_{B} n\left\{(1 / 2)(Q-\gamma Q-B)^{2} / D+Q^{2} \gamma(1-\gamma) / D\right\}$. 


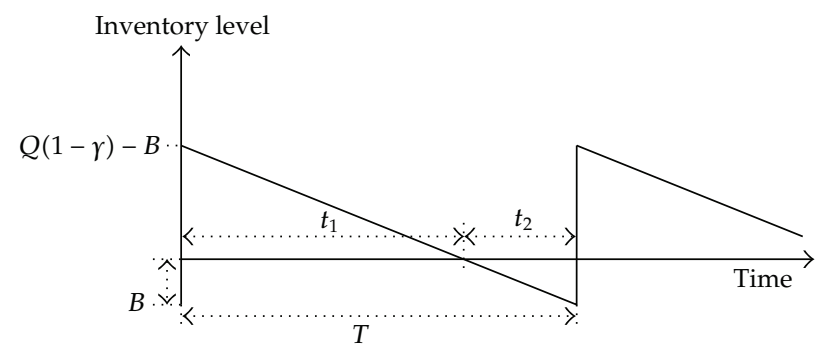

Figure 1: Behavior of the non-defective inventory level over time for the buyer.

\subsection{The Vendor's Cost per Cycle}

Figure 2 shows that the vendor's holding cost per cycle can be obtained as (see, e.g., [22, 24]):

Holding cost per cycle

$$
\begin{aligned}
& =h_{v}[\text { bold area }- \text { shaded area }] \\
& =h_{v}\left\{\left[n Q\left(\frac{Q}{P}+(n-1) T\right)-\frac{n Q(n Q / P)}{2}\right]-T[Q+2 Q+\cdots+(n-1) Q]\right\} \\
& =h_{v}\left\{\left[n Q\left(\frac{Q}{P}+(n-1) \frac{Q(1-\gamma)}{D}\right)-\frac{n Q(n Q / P)}{2}\right]-\frac{Q(1-\gamma)}{D}[Q+2 Q+\cdots+(n-1) Q]\right\} \\
& =h_{v}\left\{\frac{n Q^{2}}{P}-\frac{n^{2} Q^{2}}{2 P}+\frac{n(n-1) Q^{2}(1-\gamma)}{2 D}\right\} .
\end{aligned}
$$

After adding the setup and warranty costs for defective items, the vendor's total cost per cycle $T C_{v}(n, Q)$ is

$$
T C_{v}(n, Q)=S_{v}+v n Q \gamma+h_{v}\left\{\frac{n Q^{2}}{P}-\frac{n^{2} Q^{2}}{2 P}+\frac{n(n-1) Q^{2}(1-\gamma)}{2 D}\right\} .
$$

\subsection{The Integrated Vendor-Buyer Inventory Model}

The total vendor-buyer integrated cost per cycle is

$$
\begin{aligned}
T C_{c}(n, Q, B)= & T C_{v}(n, Q)+T C_{B}(n, Q, B)=S_{v}+S_{B}+n F+(v \gamma+d) n Q \\
& +h_{v}\left\{\frac{n Q^{2}}{P}-\frac{n^{2} Q^{2}}{2 P}+\frac{n(n-1) Q^{2}(1-\gamma)}{2 D}\right\} \\
& +h_{B} n\left\{\frac{1}{2} \frac{(Q-\gamma Q-B)^{2}}{D}+\frac{\gamma Q^{2}(1-\gamma)}{D}\right\}+b n \frac{1}{2} \frac{B^{2}}{D} .
\end{aligned}
$$

Since the replenishment cycle length $T_{c}=n Q(1-\gamma) / D$, we have

$$
E\left[T_{c}\right]=\frac{n Q(1-E[\gamma])}{D} .
$$




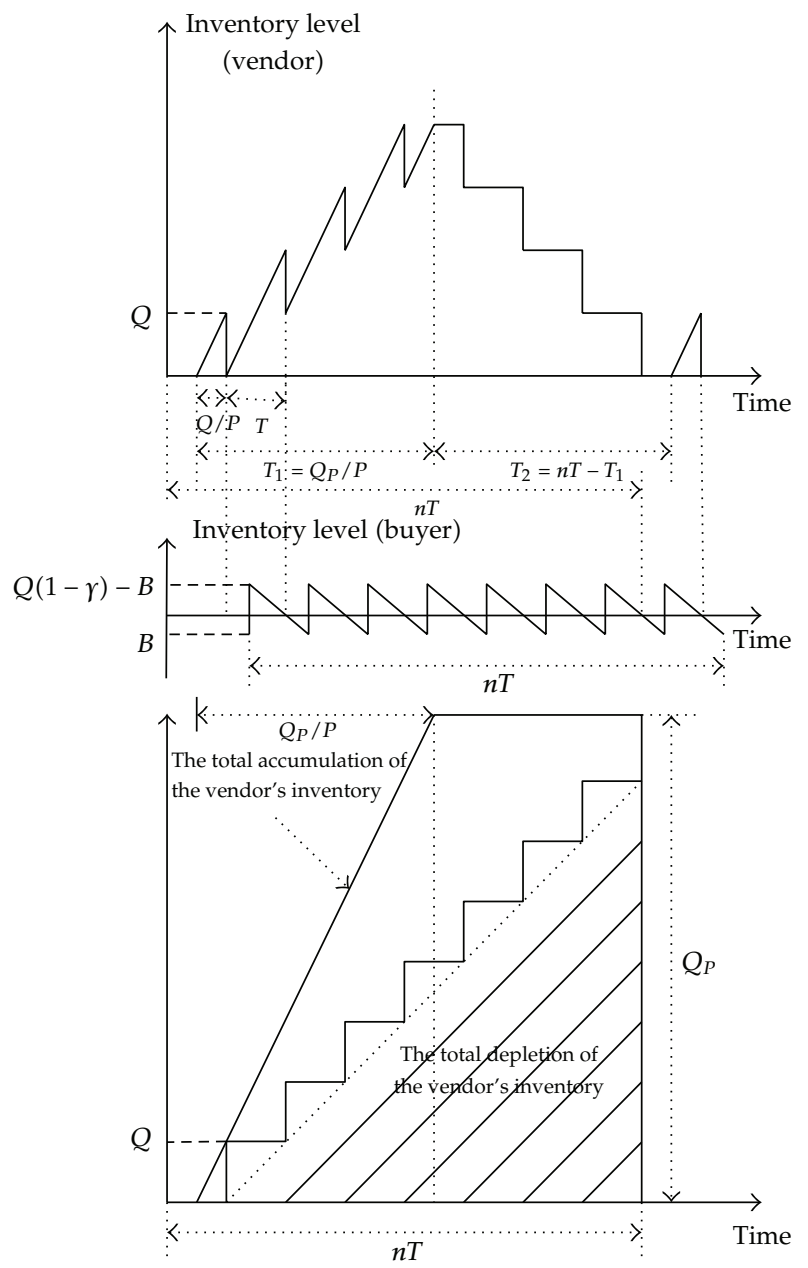

Figure 2: Behavior of the inventory over time for the vendor and the buyer.

Using the renewal-reward theorem, the expected total annual cost of the vendor and buyer is

$$
\begin{aligned}
\operatorname{ETC}(n, Q, B)= & \frac{E\left[T C_{c}(n, Q, B)\right]}{E\left[T_{C}\right]}=\frac{\left(S_{v}+S_{B}\right) D}{n Q(1-E[\gamma])}+\frac{F D}{Q(1-E[\gamma])}+\frac{(v E[\gamma]+d) D}{(1-E[\gamma])} \\
& +h_{v}\left[\frac{Q D}{P(1-E[\gamma])}-\frac{n Q D}{2 P(1-E[\gamma])}+\frac{(n-1) Q}{2}\right] \\
& +h_{B}\left\{\frac{1}{2}\left(\frac{Q E\left[(1-\gamma)^{2}\right]}{(1-E[\gamma])}-2 B+\frac{B^{2}}{Q(1-E[\gamma])}\right)+\frac{Q\left(E[\gamma]-E\left[\gamma^{2}\right]\right)}{(1-E[\gamma])}\right\} \\
& +b \frac{1}{2} \frac{B^{2}}{Q(1-E[\gamma])} .
\end{aligned}
$$


Taking the first derivative of $\operatorname{ETC}(n, Q, B)$ with respect to $Q$ and $B$, we have

$$
\begin{aligned}
\frac{\partial \mathrm{ETC}(n, Q, B)}{\partial Q}= & -\frac{\left(S_{v}+S_{B}+n F\right) D}{n Q^{2}(1-E[\gamma])}+h_{v}\left[\frac{D}{P(1-E[\gamma])}-\frac{n D}{2 P(1-E[\gamma])}+\frac{(n-1)}{2}\right] \\
& +h_{B}\left\{\frac{1}{2} \frac{E\left[(1-\gamma)^{2}\right]}{(1-E[\gamma])}-\frac{B^{2}}{2 Q^{2}(1-E[\gamma])}+\frac{\left(E[\gamma]-E\left[\gamma^{2}\right]\right)}{(1-E[\gamma])}\right\} \\
& -b \frac{1}{2} \frac{B^{2}}{Q^{2}(1-E[\gamma])}, \\
\frac{\partial \operatorname{ETC}(n, Q, B)}{\partial B}= & h_{B}\left\{-1+\frac{B}{Q(1-E[\gamma])}\right\}+b \frac{B}{Q(1-E[\gamma])} .
\end{aligned}
$$

Taking the second derivative, we have

$$
\begin{gathered}
\frac{\partial^{2} \operatorname{ETC}(n, Q, B)}{\partial Q^{2}}=\frac{2\left(S_{v}+S_{B}+n F\right) D}{n Q^{3}(1-E[\gamma])}+\frac{h_{B} B^{2}}{Q^{3}(1-E[\gamma])}+\frac{b B^{2}}{Q^{3}(1-E[\gamma])}, \\
\frac{\partial^{2} \operatorname{ETC}(n, Q, B)}{\partial B^{2}}=\frac{h_{B}}{Q(1-E[\gamma])}+\frac{b}{Q(1-E[\gamma])}, \\
\frac{\partial^{2} \operatorname{ETC}(n, Q, B)}{\partial Q \partial B}=-\frac{\left(h_{B}+b\right) B}{Q^{2}(1-E[\gamma])}, \\
\left(\frac{\partial^{2} \operatorname{ETC}(n, Q, B)}{\partial Q^{2}}\right)\left(\frac{\partial^{2} \operatorname{ETC}(n, Q, B)}{\partial B^{2}}\right)-\left(\frac{\partial^{2} \operatorname{ETC}(n, Q, B)}{\partial Q \partial B}\right)^{2} \\
=\frac{2\left(S_{v}+S_{B}+n F\right) D\left(h_{B}+b\right)}{n Q^{4}(1-E[\gamma])^{2}} .
\end{gathered}
$$

Since we assume that $E[\gamma]<1-D / P$, we have $\partial^{2} \operatorname{ETC}(n, Q, B) / \partial Q^{2}>0, \partial^{2} \operatorname{ETC}(n, Q, B) /$ $\partial B^{2}>0$, and $\left(\partial^{2} \operatorname{ETC}(n, Q, B) / \partial Q^{2}\right)\left(\partial^{2} \operatorname{ETC}(n, Q, B) / \partial B^{2}\right)-\left(\partial^{2} \operatorname{ETC}(n, Q, B) / \partial Q \partial B\right)^{2}>0$, which implies that at a particular value of $n$, the total integrated annual cost is a convex function and there exists a unique value of $Q$ and $B$ that minimize (3.6), which is given as

$$
\begin{aligned}
& Q^{*}(n) \\
& =\sqrt{\frac{2\left(S_{v}+S_{B}+n F\right) D}{n\left[h_{v}((n-1)(1-E[\gamma])+(2-n)(D / P))+h_{B}\left(E\left[(1-\gamma)^{2}\right]+2 E[\gamma]-2 E\left[\gamma^{2}\right]\right)-\mathcal{A}\right]}}, \\
& B^{*}(n)=\frac{h_{B}}{\left(h_{B}+b\right)}(1-E[\gamma]) Q^{*}(n),
\end{aligned}
$$

where $\mathcal{A}$ denotes $\left(h_{B}^{2} /\left(h_{B}+b\right)\right)(1-E[\gamma])^{2}$. 
If we take the second derivative of $\operatorname{ETC}(n, Q, B)$ with respect to $n$, we have

$$
\frac{\partial^{2} \operatorname{ETC}(n, Q, B)}{\partial n^{2}}=\frac{2\left(S_{v}+S_{B}+n F\right) D}{n^{3} Q(1-E[r])}>0,
$$

which proves that the total integrated annual cost is a convex function of $n$. Note that there is a negative term in the denominator of $Q^{*}(n)$. The proof that the denominator is positive is shown in the appendix.

\subsection{Solution Procedure}

The problem is to determine the value of $n$ that minimizes $\operatorname{ETC}(n, Q, B)$. Because the number of shipments per batch production run, $n$, is a discrete variable, one can find the optimal value of $n$ from the following procedures.

(1) For a range of $n$ values, determine the corresponding $Q^{*}(n)$ and $B^{*}(n)$ using (3.9), and compute $\operatorname{ETC}\left(n, Q^{*}(n), B^{*}(n)\right)$ by substituting $Q^{*}(n)$ and $B^{*}(n)$ into (3.6).

(2) Derive the optimal value of $n$, denoted by $n^{*}$, such that

$$
\begin{aligned}
& \operatorname{ETC}\left(n, Q^{*}(n), B^{*}(n)\right) \leq \operatorname{ETC}\left(n-1, Q^{*}(n-1), B^{*}(n-1)\right) \text { and } \\
& \operatorname{ETC}\left(n, Q^{*}(n), B^{*}(n)\right) \leq \operatorname{ETC}\left(n+1, Q^{*}(n+1), B^{*}(n+1)\right) .
\end{aligned}
$$

Once we obtain the $n^{*}$ value, the optimal size of a production batch $Q_{P}{ }^{*}$ is given by $Q_{P}{ }^{*}=$ $n^{*} Q^{*}\left(n^{*}\right)$.

\subsection{The Buyer's Independent Optimal Solution}

Considering the buyer's independent decision process, the buyer's expected annual cost is given as

$$
\begin{aligned}
\operatorname{ETC}_{B}(Q, B)= & \frac{S_{B} D}{Q(1-E[\gamma])}+\frac{F D}{Q(1-E[\gamma])}+\frac{d D}{(1-E[\gamma])} \\
& +h_{B}\left\{\frac{1}{2}\left(\frac{Q E\left[(1-\gamma)^{2}\right]}{(1-E[\gamma])}-2 B+\frac{B^{2}}{Q(1-E[\gamma])}\right)+\frac{Q\left(E[\gamma]-E\left[r^{2}\right]\right)}{(1-E[\gamma])}\right\} \\
& +b \frac{1}{2} \frac{B^{2}}{Q(1-E[\gamma])},
\end{aligned}
$$

and the optimal solution is

$$
\begin{gathered}
Q_{B}{ }^{*}=\sqrt{\frac{2\left(S_{B}+F\right) D}{\left[h_{B}\left(E\left[(1-\gamma)^{2}\right]+2 E[\gamma]-2 E\left[\gamma^{2}\right]\right)-\left(h_{B}{ }^{2} /\left(h_{B}+b\right)\right)(1-E[\gamma])^{2}\right]}}, \\
B_{B}{ }^{*}=\frac{h_{B}}{\left(h_{B}+b\right)}(1-E[\gamma]) Q_{B}{ }^{*} .
\end{gathered}
$$


The vendor's expected annual cost is given as

$$
\operatorname{ETC}_{v}(Q)=\frac{S_{v} D}{Q(1-E[\gamma])}+\frac{v E[\gamma] D}{(1-E[\gamma])}+h_{v} \frac{Q D}{2 P(1-E[\gamma])}
$$

If the decision is made solely from the buyer's perspective, then substituting $Q=Q_{B}{ }^{*}$ and $B=B_{B}{ }^{*}$ into (3.11), and $Q=Q_{B}{ }^{*}$ into (3.13), we obtain the buyer's and the vendor's expected annual costs, respectively.

\section{Numerical Examples and Sensitivity Analysis}

Consider an integrated vendor-buyer cooperative inventory model with the following parameters.

Production rate, $P=160,000$ units / year

Demand rate, $D=50,000$ units /year

Setup cost for vendor, $S_{v}=\$ 300 /$ production run

Ordering cost for buyer, $S_{B}=\$ 100 /$ order

Holding cost for vendor, $h_{v}=\$ 2 /$ unit/year

Holding cost for buyer, $h_{B}=\$ 5 /$ unit/year

Freight (transportation) cost, $F=\$ 25 /$ delivery

Screening cost, $d=\$ 0.5 /$ unit

Backordering cost, $b=\$ 10 /$ unit/year

The warranty cost of defective items, $v=\$ 30 /$ unit.

If the defective percentage follows a uniform distribution with

$$
f(\gamma)= \begin{cases}\frac{1}{\beta^{\prime}} & 0 \leq \gamma \leq \beta \\ 0, & \text { otherwise }\end{cases}
$$

then we have

$$
\begin{gathered}
E[\gamma]=\int_{0}^{\beta} r f(\gamma) d \gamma=\int_{0}^{\beta} \frac{\gamma}{\beta} d \gamma=\frac{\beta}{2}, \\
E\left[\gamma^{2}\right]=\int_{0}^{\beta} \gamma^{2} f(\gamma) d \gamma=\int_{0}^{\beta} \frac{\gamma^{2}}{\beta} d \gamma=\frac{\beta^{2}}{3}, \\
E\left[(1-\gamma)^{2}\right]=\int_{0}^{\beta}(1-\gamma)^{2} f(\gamma) d \gamma=\int_{0}^{\beta} \frac{(1-\gamma)^{2}}{\beta} d \gamma=1-\beta+\frac{\beta^{2}}{3} .
\end{gathered}
$$

Specifically, when $\beta=0.04$, we obtain the results given in Table 1 . The optimal solution is $n^{*}=6, Q^{*}=925.72, B^{*}=302.40, Q_{P}{ }^{*}=5,554.34$, and the integrated total cost per year 
Table 1: Optimal solutions of $n . P=160,000, D=50,000, S_{v}=300, S_{B}=100, F=25, h_{v}=2, h_{B}=5, d=0.5$, $b=10, v=30$, and $\beta=0.04$.

\begin{tabular}{lccc}
\hline$n$ & $Q^{*}(n)$ & $B^{*}(n)$ & $\mathrm{ETC}\left(n, Q^{*}(n), B^{*}(n)\right)$ \\
\hline 1 & $3,250.8088$ & $1,061.9309$ & $69,462.9280$ \\
2 & $2,049.4812$ & 669.4972 & $67,324.8856$ \\
3 & $1,538.2220$ & 502.4859 & $66,625.7848$ \\
4 & $1,247.9219$ & 407.6545 & $66,343.5233$ \\
5 & $1,059.0539$ & 345.9576 & $66,239.2955$ \\
$6^{*}$ & $925.7239^{*}$ & $302.4031^{*}$ & $66,226.6941^{*}$ \\
7 & 826.2700 & 269.9149 & $66,266.7405$ \\
\hline
\end{tabular}

"Denotes the aptimal solution.

is $\$ 66,226.69$. If the decision is made solely from the buyer's perspective, then the optimal value of $Q_{B}{ }^{*}=1,918.35, B_{B}{ }^{*}=626.66$, the buyer's expected annual cost is $\$ 32,159.19$, and the vendor's expected annual cost is $\$ 39,202.75$. Therefore, the integrated cost reduction is $\$ 32,159.19+\$ 39,202.75-\$ 66,226.69=\$ 5,135.25$.

Table 2 shows the optimal solutions for different freight (transportation) costs. When the freight cost $F$ increases, the optimal number of shipments per production batch from the vendor to the buyer decreases, while both the optimal size of the shipments and the maximum backordering quantity increase. It is interesting to see from Table 3 that when the vendor's holding $\operatorname{cost} h_{v}$ is less than the buyer's holding $\operatorname{cost} h_{B}$, the behavior of the optimal solutions of the three decision variables $\left(n^{*}, Q^{*}, B^{*}\right)$ has a similar relationship as the freight cost (i.e., when the cost increases, the value of $n^{*}$ decreases, while both $Q^{*}$ and $B^{*}$ increase). However, when the vendor's holding cost is the same as the buyer's holding cost $\left(h_{v}=\right.$ $\left.h_{B}=5\right)$, both $Q^{*}$ and $B^{*}$ decrease. From Table 4 , one can see that as the buyer's holding cost increases, the optimal size of the shipments decreases. The lager the buyer's holding cost, the greater the cost reduction of the integrated model in comparison to an independent decision by the buyer.

Table 5 shows that as the backordering cost $b$ increases, both the optimal size of the shipments and the maximum backordering quantity decrease. When backorders are not permitted (i.e., $b=\infty$ ), the optimal solution is to have 7 shipments per production batch, and the optimal size of the shipments is $Q^{*}=776.25$. From Table 5, one can see that if backorders are permitted, the expected total annual integrated cost is less than that when backorders are not permitted. The integrated cost reduction also increases as the backordering cost increases.

Table 6 shows the sensitivity analysis on the defective percentage $\gamma$ (we assume that $\gamma$ is uniformly distributed between 0 and $\beta$ ). It is interesting to note that when $\beta$ increases, the maximum backordering quantity decreases. The larger the $\beta$ value, the greater the cost reduction of the integrated model in comparison to an independent decision by the buyer. From the numerical examples, one can see that the integrated model results in an impressive cost reduction in comparison to an independent decision by the buyer.

\section{Conclusion and Future Research}

In this paper, we consider an integrated vendor-buyer inventory policy for items with imperfect quality and shortage backordering. The objective is to minimize the total joint annual costs incurred by the vendor and the buyer. The production process is imperfect and produces a certain number of defective items with a known probability density function. 


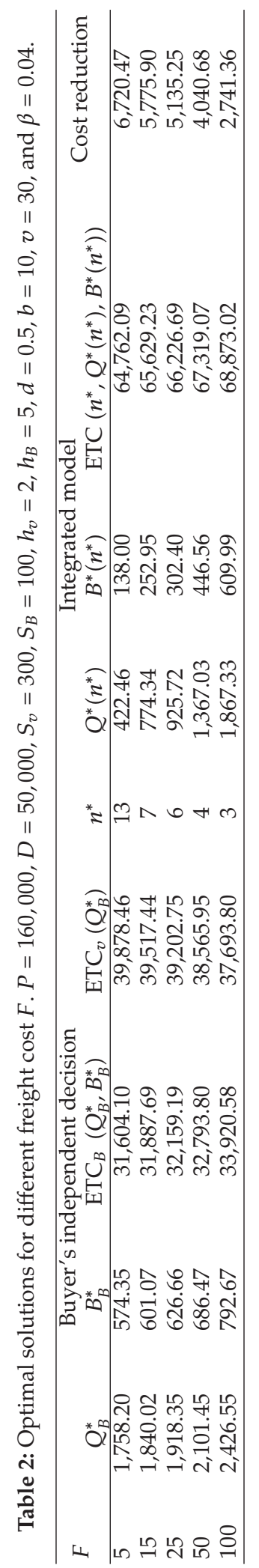




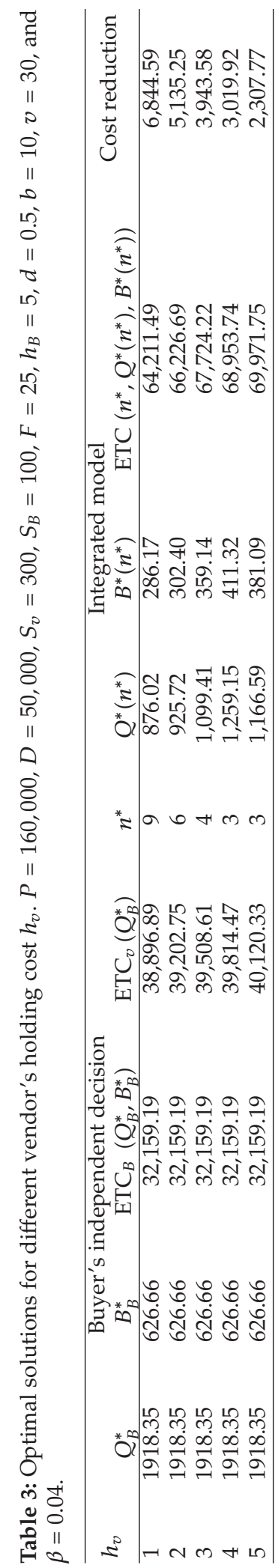




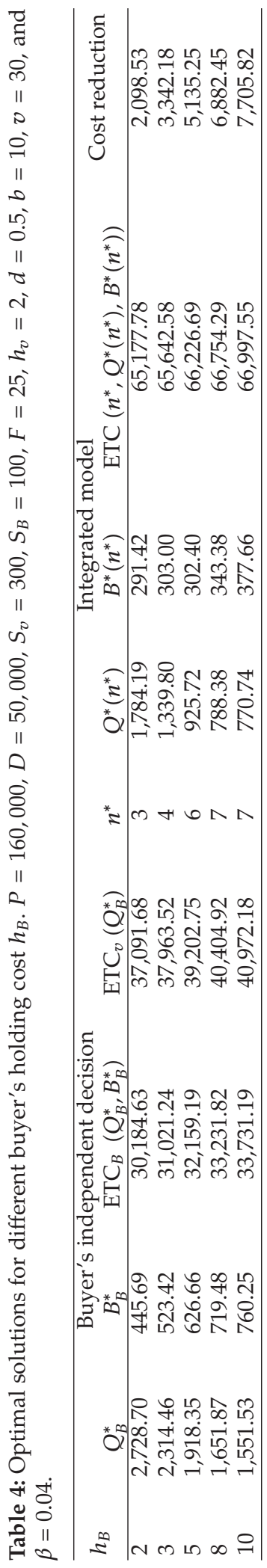




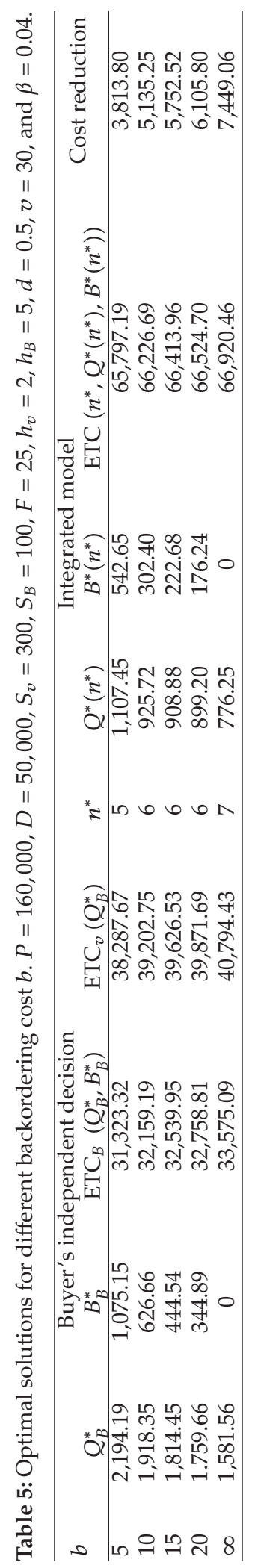




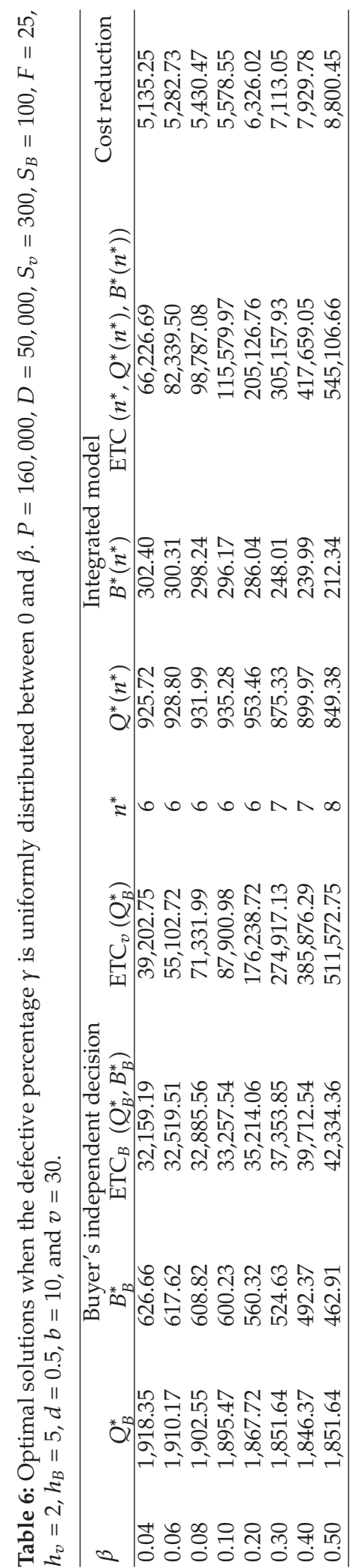


Shortages are permitted and are completely backordered. We consider the policy in which the quantity delivered to the buyer is identical at each shipment. The expected total annual integrated cost is derived and a solution procedure is provided to find the optimal solution. Numerical examples show that the integrated model gives an impressive cost reduction in comparison to an independent decision by the buyer. The results also show that if backorders are permitted, the expected annual cost is less than when backorders are not permitted. Therefore, if customers are willing to wait for the next shipment when a shortage occurs, it is profitable for the company to allow backorders although it incurs a penalty cost for the delay.

There are several possible extensions of this work. One immediate extension is instead of inspecting the items at the buyer's place, one may consider having the vendor inspect the items while they are being produced and deliver good-quality items to the buyer. This paper assumes that shortages are completely backordered. One possible extension of this research is to consider the case of partial backordering, with either a constant or a variable backordering rate. Another extension of our model is to follow Khan et al. [32] and Hsu [33] by considering the possibility of incorrectly classifying a non-defective item as defective (a type I error), or incorrectly classifying a defective item as nondefective (a type II error). Thus, some defective items may be sold to customers, who in turn will detect the quality problem and return them to the buyer. Finally, instead of selling the defective items at a discounted price to a secondary market, the vendor may rework the defective items and convert the defective items into goodquality products to satisfy the buyer's demand.

\section{Appendix}

To prove that

$$
\begin{aligned}
n & {\left[h_{v}\left((n-1)(1-E[\gamma])+(2-n) \frac{D}{P}\right)+h_{B}\left(E\left[(1-\gamma)^{2}\right]+2 E[\gamma]-2 E\left[\gamma^{2}\right]\right)\right.} \\
& \left.-\frac{h_{B}^{2}}{\left(h_{B}+b\right)}(1-E[\gamma])^{2}\right]>0,
\end{aligned}
$$

recall that we assume $E[\gamma]<1-D / P$, that is, $1-E[\gamma]>D / P$. Thus, we have $h_{v}((n-$ 1) $(1-E[\gamma])+(2-n)(D / P))>h_{v}((n-1)(D / P)+(2-n)(D / P))=h_{v}(D / P)>0$. Note that $h_{B}\left(E\left[(1-\gamma)^{2}\right]+2 E[\gamma]-2 E\left[\gamma^{2}\right]\right)-h_{B}^{2} /\left(h_{B}+b\right)(1-E[\gamma])^{2}=h_{B}\left(1-E\left[\gamma^{2}\right]\right)-h_{B}^{2} /\left(h_{B}+b\right)(1-E[\gamma])^{2}$. Since $\gamma$ is a random variable between 0 and 1 , we have $E\left[\gamma^{2}\right]<E[\gamma]$. Thus,

$$
\begin{gathered}
h_{B}\left(1-E\left[\gamma^{2}\right]\right)-\frac{h_{B}^{2}}{\left(h_{B}+b\right)}(1-E[\gamma])^{2}>h_{B}(1-E[\gamma])-\frac{h_{B}^{2}}{\left(h_{B}+b\right)}(1-E[\gamma])^{2}, \\
h_{B}(1-E[\gamma])-\frac{h_{B}^{2}}{\left(h_{B}+b\right)}(1-E[\gamma])^{2}=h_{B}(1-E[\gamma])\left(1-\frac{h_{B}}{\left(h_{B}+b\right)}(1-E[\gamma])\right) .
\end{gathered}
$$

Since $h_{B}>0,1-E[\gamma]>D / P$, and $\left(1-h_{B} /\left(h_{B}+b\right)(1-E[\gamma])\right)=b /\left(h_{B}+b\right)+h_{B} /\left(h_{B}+b\right) E[\gamma]>0$, we have $h_{B}(1-E[\gamma])\left(1-h_{B} /\left(h_{B}+b\right)(1-E[\gamma])\right)>0$. This proves that the denominator of $Q^{*}(n)$ is positive. 


\section{References}

[1] M. Cao and Q. Zhang, "Supply chain collaborative advantage: a firm's perspective," International Journal of Production Economics, vol. 128, no. 1, pp. 358-367, 2010.

[2] S. K. Goyal, "An integrated inventory model for a single supplier-single customer problem," International Journal of Production Research, vol. 15, no. 1, pp. 107-111, 1977.

[3] A. Banerjee, "A joint economic-lot-size model for purchaser and vendor," Decision Sciences, vol. 17, no. 3, pp. 292-311, 1986.

[4] S. K. Goyal and A. Z. Szendrovits, "A constant lot size model with equal and unequal sized batch shipments between production stages," Engineering Costs and Production Economics, vol. 10, no. 1, pp. 203-210, 1986.

[5] S. K. Goyal, "A joint economic-lot-size model for purchaser and vendor: a comment," Decision Sciences, vol. 19, no. 1, pp. 236-241, 1988.

[6] S. K. Goyal and Y. P. Gupta, "Integrated inventory models: the buyer-vendor coordination," European Journal of Operational Research, vol. 41, no. 3, pp. 261-269, 1989.

[7] J. F. Affisco, M. J. Paknejad, and F. Nasri, “Comparison of alternative joint vendor-purchaser lot-sizing models," International Journal of Production Research, vol. 31, no. 11, pp. 2661-2676, 1993.

[8] R. Aderohunmu, A. Mobolurin, and N. Bryson, "Joint vendor-buyer policy in JIT manufacturing," Journal of the Operational Research Society, vol. 46, no. 3, pp. 375-385, 1995.

[9] L. Lu, "A one-vendor multi-buyer integrated inventory model," European Journal of Operational Research, vol. 81, no. 2, pp. 312-323, 1995.

[10] S. K. Goyal, "A one-vendor multi-buyer integrated inventory model: a comment," European Journal of Operational Research, vol. 82, no. 1, pp. 209-210, 1995.

[11] R. M. Hill, "The single-vendor single-buyer integrated production-inventory model with a generalised policy," European Journal of Operational Research, vol. 9, no. 3, pp. 493-499, 1997.

[12] D. Ha and S. L. Kim, "Implementation of JIT purchasing: an integrated approach," Production Planning and Control, vol. 8, no. 2, pp. 152-156, 1997.

[13] S. Viswanathan, "Optimal strategy for the integrated vendor-buyer inventory model," European Journal of Operational Research, vol. 105, no. 1, pp. 38-42, 1998.

[14] R. M. Hill, "The optimal production and shipment policy for the single-vendor single-buyer integrated production-inventory problem," International Journal of Production Research, vol. 37, no. 11, pp. 2463-2475, 1999.

[15] M. A. Hoque and S. K. Goyal, "An optimal policy for a single-vendor single-buyer integrated production-inventory system with capacity constraint of the transport equipment," International Journal of Production Economics, vol. 65, no. 3, pp. 305-315, 2000.

[16] S. K. Goyal and F. Nebebe, "Determination of economic production-shipment policy for a singlevendor-single-buyer system," European Journal of Operational Research, vol. 121, no. 1, pp. 175-178, 2000.

[17] K. S. Wu and L. Y. Ouyang, "An integrated single-vendor single-buyer inventory system with shortage derived algebraically," Production Planning and Control, vol. 14, no. 6, pp. 555-561, 2003.

[18] K. J. Chung, "An improvement of an integrated single-vendor single-buyer inventory model with shortage," Production Planning and Control, vol. 19, no. 3, pp. 275-277, 2008.

[19] M. Ben-Daya and A. Al-Nassar, "An integrated inventory production system in a three-layer supply chain," Production Planning and Control, vol. 19, no. 2, pp. 97-104, 2008.

[20] M. K. Salameh and M. Y. Jaber, "Economic production quantity model for items with imperfect quality," International Journal of Production Economics, vol. 64, no. 1, pp. 59-64, 2000.

[21] C. K. Huang, "An integrated vendor-buyer cooperative inventory model for items with imperfect quality," Production Planning and Control, vol. 13, no. 4, pp. 355-361, 2002.

[22] S. K. Goyal, C. K. Huang, and K. C. Chen, "A simple integrated production policy of an imperfect item for vendor and buyer," Production Planning and Control, vol. 14, no. 7, pp. 596-602, 2003.

[23] S. K. Goyal and L. E. Cárdenas-Barrón, "Note on: economic production quantity model for items with imperfect quality - a practical approach," International Journal of Production Economics, vol. 77, no. 1, pp. 85-87, 2002.

[24] C. K. Huang, "An optimal policy for a single-vendor single-buyer integrated production-inventory problem with process unreliability consideration," International Journal of Production Economics, vol. 91, no. 1, pp. 91-98, 2004. 
[25] S. T. Lo, H. M. Wee, and W. C. Huang, "An integrated production-inventory model with imperfect production processes and Weibull distribution deterioration under inflation," International Journal of Production Economics, vol. 106, no. 1, pp. 248-260, 2007.

[26] H. M. Wee, J. Yu, and M. C. Chen, "Optimal inventory model for items with imperfect quality and shortage backordering," Omega, vol. 35, no. 1, pp. 7-11, 2007.

[27] B. Maddah and M. Y. Jaber, "Economic order quantity for items with imperfect quality: revisited," International Journal of Production Economics, vol. 112, no. 2, pp. 808-815, 2008.

[28] S. H. Yoo, D. Kim, and M. S. Park, "Economic production quantity model with imperfect-quality items, two-way imperfect inspection and sales return," International Journal of Production Economics, vol. 121, no. 1, pp. 255-265, 2009.

[29] L. E. Cárdenas-Barrón, "Economic production quantity with rework process at a single-stage manufacturing system with planned backorders," Computers and Industrial Engineering, vol. 57, no. 3, pp. 1105-1113, 2009.

[30] H. C. Chang and C. H. Ho, "Exact closed-form solutions for "optimal inventory model for items with imperfect quality and shortage backordering"," Omega, vol. 38, no. 3-4, pp. 233-237, 2010.

[31] S. S. Sana, "An economic production lot size model in an imperfect production system," European Journal of Operational Research, vol. 201, no. 1, pp. 158-170, 2010.

[32] M. Khan, M. Y. Jaber, and M. Bonney, "An economic order quantity (EOQ) for items with imperfect quality and inspection errors," International Journal of Production Economics, vol. 133, no. 1, pp. 113-118, 2011.

[33] L. F. Hsu, "A note on, "An economic order quantity (EOQ) for items with imperfect quality and inspection errors"," International Journal of Industrial Engineering Computations, vol. 3, no. 4, pp. 695702, 2012.

[34] J. T. Hsu and L. F. Hsu, “An integrated vendor-buyer cooperative inventory model in an imperfect production process with shortage backordering," International Journal of Advanced Manufacturing Technology. In press.

[35] J. T. Hsu and L. F. Hsu, "A note on, "Optimal inventory model for items with imperfect quality and shortage backordering," International Journal of Industrial Engineering Computations, vol. 3, no. 5, pp. 939-948, 2012.

[36] C. D. J. Waters, Inventory Control and Management, Wiley, Hoboken, NJ, USA, 2nd edition, 2003. 


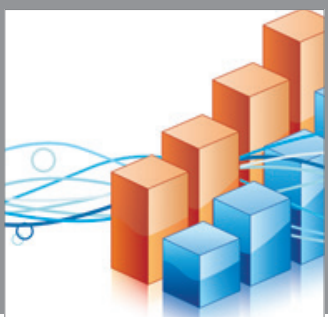

Advances in

Operations Research

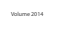

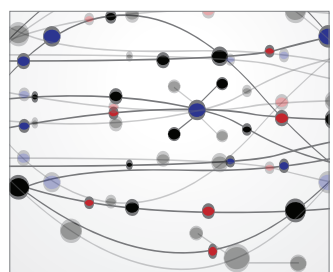

\section{The Scientific} World Journal
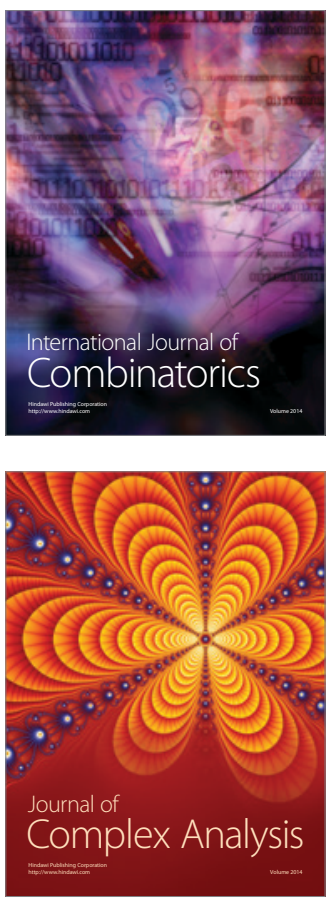

International Journal of

Mathematics and

Mathematical

Sciences
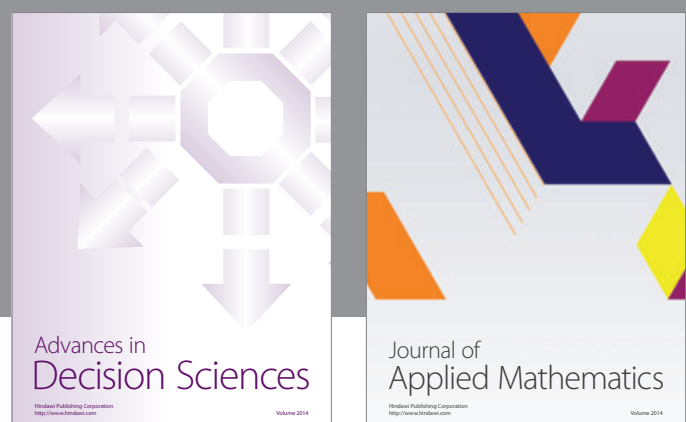

Journal of

Applied Mathematics
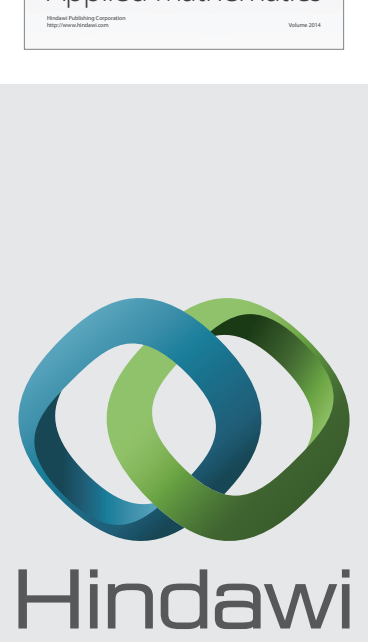

Submit your manuscripts at http://www.hindawi.com
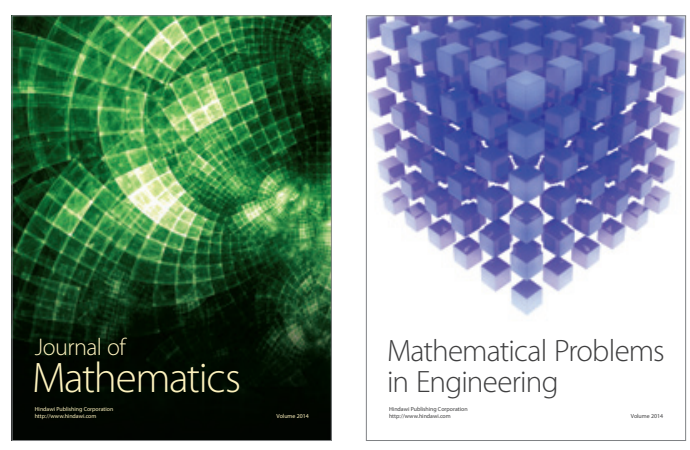

Mathematical Problems in Engineering
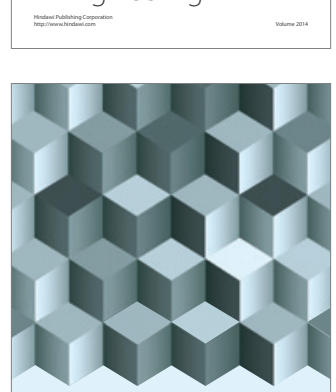

Journal of

Function Spaces
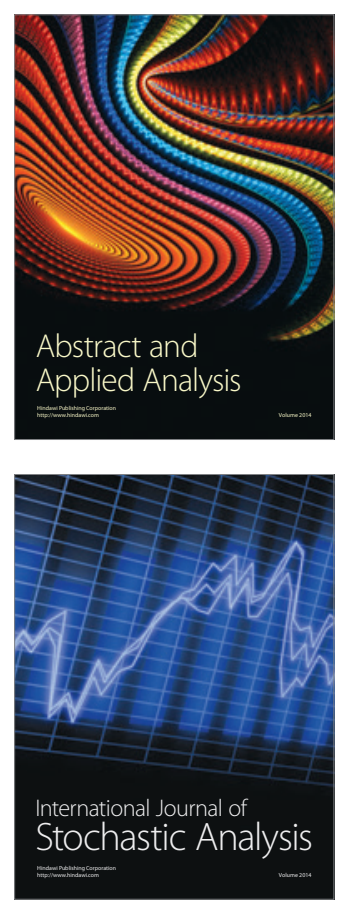

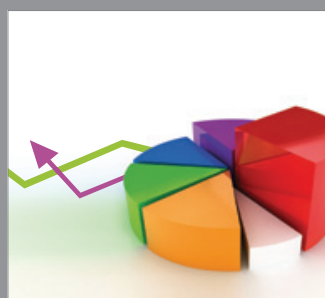

ournal of

Probability and Statistics

Promensencen
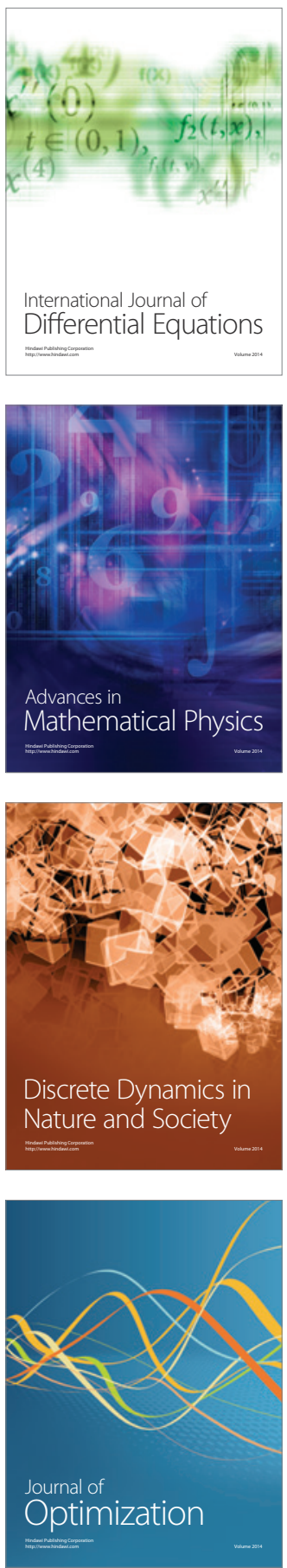